\title{
Electromyographic gradients as a function of tracking cues '
}

\author{
ALEXANDER K. BARTOSHUK AND JON A. KASWICK \\ BROWN UNIVERSITY
}

Malmo's (1965) arousal gradient hypothesis apparently requires heart rate (HR) gradients during tracking of somesthetic cues in the absence of EMG gradients. A pressure tracking task was performed by 14 undergraduates with visual cues (VT) and while blindfolded. HR gradients occurred concomitantly with EMG gradients during VT, but not during blindfolded tracking when significant intratrial changes in EMGs were prevented.

Monotonically increasing electromyographic potentials (EMG gradients) occur within trials on psychomotor tasks with controls for physical factors (e.g., work done). At McGill University, 16 of 17 studies revealed EMG gradients (Malmo, 1965); elsewhere, EMG gradients have been reported by Eason (1959), Pishkin \& Wolfgang (1964). Bartoshuk (1955) hypothesized that EMG gradient steepness is an indicant of motivation; this is supported by data on task interruption (analogous to the Zeigarnik effect), performance, incentives, and task interest. Similar rising gradients occur in heart rate (HR), blood pressure and respiration; palmar conductance (PC) gradients are falling ones. Aside from PC data, the general rule seems to be an increasing "tonic" level of physiological activity within trials on psychomotor tasks. Concomitant EEG gradients do not occur. Malmo (1965) proposed increasing activity in the arousal system which, via the ascending reticular activating system, maintains a constant level of cortical activation (to compensate for cortical adaptation or fatigue); concurrently, the same arousal signal, via the descending reticular facilatory system, produces rising gradients in peripheral tonus because peripheral components are less susceptible to adaptation or fatigue.

We asked Ss to exert constant pressure on a finger button while blindfolded; Ss could use somesthetic cues, and in a related task rising EMG gradients did not occur (Eason, 1959). For Malmo's proposal, successful tracking in this task would apparently require increasing arousal to compensate for adaptation or fatigue in cortical circuits, and this should be reflected in a rising HR gradient.

Method

Ss were one female and 13 male undergraduates; nine were right- and five left-handed.

For initial blindfolded (IB) trials 1-5, Ss were guided a few seconds until they were exerting correctpressure $(241 \mathrm{gm})$; then they were required to maintain it, with only somesthetic cues as feedback. During trials 6-10, they visually tracked (VT) a polygraphic tracing of their pressure; Ss were asked to keep a pen on a red line which represented a constant deflection of $20 \mathrm{~mm}$ (pressure $=241 \mathrm{gm}$ ). On the last five trials, blindfolded conditions were repeated (FB). During VT the standard for correct pressure was continuously present, whereas during IB and FB Ss had to rely on a "memory trace" of sensory cues from the start of a trial. E instructed $S$ when to start and stop. Each trial lasted $75 \mathrm{sec}$.; intertrial intervals were usually 45 sec., occasionally longer. Ten Ss had 15 trials consisting of three blocks of five trials: $1-5$ (IB); 6-10 (VT); 11-15 (FB). Initial four Ss had 20 trials: $1-5$ (IB); $6-15$ (VT); $16-20$ (FB); we only used data from trials 1-5, 6-10, and 16-20. All Ss wore earphones; white noise to right ear masked apparatus sounds.

Felt-padded, silver cup electrodes were attached with collodion. We recorded bipolar EMGs (electrodes 2 in. apart) on a Grass Model 6 EEG and FM tape with an Ampex SP-300. The four EMG tracings were: flexors and extensors respectively from each forearm (Bartoshuk, 1955). Also recorded continuously were EKG and pressure of active index finger on a button.

In analyses, to omit starting transients, the latter $60 \mathrm{sec}$. of a trial were divided into thirds. For HR we counted interbeat intervals and fractions thereof. Tracking scores were derived from 40 measures of pen deflections for each $20 \mathrm{sec}$. Taped EMGs were replayed, rectified, led to a Grass electronic integrator, hp digital voltmeter and printer. The system was calibrated with $45 \mathrm{cps}$ sine wave signals from an hp function generator led to the EEG electrode input box, amplified with the time constant and filter settings used to record EMGs, taped and replayed as EMGs.

Friedman nonparametric analyses were run for intratrial effects (i.e., occurrence of gradients), and for treatment effects (IB, VT, FB) on gradients (i.e., change from $0-20$ "' (sec.) to 41-60'"). Group means are based on each S's median for each block of five trials.

\section{Results and Discussion}

Active arm EMGs and pressure (Table 1) are in good agreement with Eason's (1959) data: reliable EMG gradients did not occur in the active arm during IB trials and pressure decreased concurrently; we required about $1 / 60$ th the force $(0.5 \mathrm{vs} .30 \mathrm{lbs})$ and observed about $1 / 55$ th mean flexor microvoltages (averaged for all conditions: approximately $20 \mathrm{vs} .1100 \mu \mathrm{v})$. Flexor EMGs were higher $(p<.001)$ for active than passive arm during IB, VT, and FB. F tests of variances of active arm flexor and extensor EMGs during IB were not reliably different between 0-20" and 41-60" Thus Ss appeared to be successfully tracking EMG level in the active forearm during IB. 
Table 1. Mean group results for three treatments

\begin{tabular}{|c|c|c|c|c|}
\hline \multirow[t]{2}{*}{ Response measure } & \multicolumn{3}{|c|}{ Segment of trial } & \multirow{2}{*}{$\begin{array}{l}\text { Signif. } \\
\text { column } \\
\text { diff.* }\end{array}$} \\
\hline & $0-20^{\prime \prime}$ & $21-40^{\prime \prime}$ & $41-60^{\prime \prime}$ & \\
\hline \multicolumn{5}{|l|}{ Active flexor $(\mu v)$} \\
\hline IB & 17.0 & 16.3 & 16.0 & .76 \\
\hline VT & 21.1 & 24.1 & 26.4 & .002 \\
\hline FB & 18.3 & 19.2 & 20.6 & .07 \\
\hline IB vs VT vs FB & & & & .02 \\
\hline \multicolumn{5}{|l|}{ Heart rate (bpro) } \\
\hline IB & 72.2 & 73.8 & 72.4 & .02 \\
\hline VT & 70.0 & 71.2 & 71.3 & .01 \\
\hline FB & 71.8 & 72.5 & 72.7 & .56 \\
\hline IB vs VT vs FB & & & & .25 \\
\hline \multicolumn{5}{|l|}{ Performance $(\mathrm{mm})^{* *}$} \\
\hline IB & 16.3 & 15.4 & 15.1 & .04 \\
\hline VT & 19.9 & 20.0 & 20.0 & - \\
\hline $\mathrm{FB}$ & 18.7 & 18.5 & 18.7 & $\overline{1}$ \\
\hline $\mathrm{IB}$ vs VT vs $\mathrm{FB}$ & & & & .21 \\
\hline \multicolumn{5}{|c|}{ Total distance off $(\mathrm{mm})$} \\
\hline IB & 154.6 & 203.1 & 218.7 & .001 \\
\hline VT & 6.6 & 3.4 & 4.7 & .11 \\
\hline FB & 96.9 & 117.5 & 136.4 & .01 \\
\hline IB vs VT vs FB & $\cdot$ & & & .002 \\
\hline
\end{tabular}

* Some values included to indicate they were not close to significance.

** Perfect tracking required $20.0 \mathrm{~mm}$ deflection.

For HR during IB trials, the increase from 0-20" to 21-40" and decrease from 21-40"' to 41-60" were both reliable $(\mathrm{p}<.02) ; 0-20$ ' and $41-60^{\prime \prime}$ were not reliably different. When HR for all 10 blindfolded trials was used, intratrial changes did not approach significance $(p=.3)$ 。

Mean extensor EMGs were higher in active than passive arm (66 vs. $15 \mu \mathrm{v}, \mathrm{p}<.01$ ). Reliable extensor gradients did not occur, but flexor gradients were not significantly greater than extensor ones in the active arm during VT.

Passive arm flexor EMGs for IB, VT, and FB averaged $5.4 \mu \mathrm{v}$; "gradients" were observed $(p<.03)$ during IB, VT, and FB, but they did notdiffer with treatments. These passive arm flexor gradients averaged only 0.8 $\mu \mathrm{v}$. During VT, flexor gradients in active arm were reliably greater $(p<.02)$ than in passive arm.

For VT, steeper flexor EMG gradients in the active arm tended to be related to better total distance off target scores ( $r h o=-.36, p>.05$ ).

After the experiment most Ss reported that they applied "corrections" of increased pressure during
FB. Some Ss reasoned that a lapse of attention led to too little pressure; some Ss also noticed during VT that it felt as if they had to press harder near the end of a trial to maintain constant pen deflection. These "corrections" sometimes went above $20 \mathrm{~mm}$; they stabilized mean pressure, but did not eliminate gradients in total distance off target. During IB and FB, it was difficult to guide Ss exactly to $20 \mathrm{~mm}$; the error in initial mean pressure apparently had no important effect on the gradients studied.

With regard to Malmo's a rousal gradient hypothesis, even during VT the HR gradients represent only a $2 \%$ change whereas active flexor gradients average $25 \%$. Similar figures for trials of about $2.5 \mathrm{~min}$. (Malmo, 1965 , p. 229) are $5 \%$ for $\mathrm{HR}$ and respiration but over $100 \%$ for pronator teres EMGs. Nor is it clear how Malmo's arousal gradient hypothesis could predict EMG gradients in flexors but not extensors during VT, or steeper gradients in active than passive arm. More crucial, perhaps, is the failure to find monotonically rising HR gradients during blindfolded conditions where they are apparently required by Malmo's arousal gradient hypothesis.

Data on human Ss appear to be consistent with the possibility that cardiovascular gradients observed accompanying EMG gradients, as in our VT condition, may be due to cardiovascular adjustments to amount of skeletal activity. Intratrial gradients in general arousal level may not be necessary to produce EMG gradients; instead, selective facilitation may be sufficient (Bartoshuk, 1966).

\section{References}

Bartoshuk, A. K. Electromyographic gradients as indicants of motivation. Canad. J. Psychol., 1955, 9, 215-230.

Bartoshuk, A. K. Motivation. Dubuque, Iowa: Wm. C. Brown, 1966.

Eason, R. G. The surface el ectromyogram (EMG) gauges subjective effort. Percept. mot. Skills, 1959, 9, 359-361.

Malmo, R. B. Physiological gradients and behavior. Psychol. Bull., 1965, 64, 225-234.

Pishkin, V., \& Wolfgang, A. Electromyographic gradients in concept identification with numbers of irrelevant dimensions. $J$. clin. Psychol., 1964, 20, 61-67.

\section{Note}

1. Based on Kaswick's honor thesis at Brown University. Supported in part by USPHS Grants HD-01814 and Research Career Development Award K3-MH-21,837. We thank E. Doherty for assistance with data collection and reduction. 